\title{
Effect of Carbon Content, Salinity and pH on Spirulina platensis for Phycocyanin, Allophycocyanin and Phycoerythrin Accumulation
}

\author{
Gaurav Sharma ${ }^{1}$, Manoj Kumar ${ }^{2}$, Mohammad Irfan Ali' ${ }^{1}$ and Nakuleshwar Dut Jasuja ${ }^{1 *}$ \\ ${ }^{1}$ School of Sciences, Suresh Gyan Vihar University, Rajasthan, India \\ ${ }^{2}$ Marine Biotechnology Laboratory, Department of Botany, University of Delhi, North Campus, Delhi, India
}

\begin{abstract}
The cyanobacterium Spirulina platensis is an attractive source of the biopigment, which is used as a natural colour in food, cosmetic, pharmaceutical products and have tremendous applications in nutraceuticals, therapeutics and biotechnological research. The present study examines the possibility of increasing the content of Phycocyanin, Allophycocyanin, Phycoerythrin and Carotenoids under stress conditions including different $\mathrm{pH}$, salinity and carbon content in S. platensis isolated from Jalmahal, Jaipur (Rajasthan). The production of Phycocyanin, Allophycocyanin and Phycoerythrin were enhanced with $0.4 \mathrm{M} \mathrm{NaCl}, \mathrm{pH} 7$ and Carbon deficiency as compared to standard.
\end{abstract}

Keywords: Spirulina platensis; Phycobilliproteins; Chlorophyll-a; Carotenoids; Abiotic stress

\section{Introduction}

Spirulina platensis has been commercially used in several countries as health foods [1,2], feed [3], bio-fertilizers [4] and applications in biotechnology [5] because of its valuable constituents such as proteins, vitamins, minerals, carbohydrates, lipids and polyunsaturated fatty acids. They have anti-cancer properties [6] and immune promoting effects [7]. S. platensis is an attractive source of various bioactive substances such as sterols function as antimicrobial agents $[8,9]$, polysulfated polysaccharides as antiviral agents [10], phycobilliproteins and carotenoids as antioxidants [11], mycosporine-like amino acids (MAAs) and scytonemin as photoprotectants [12], polyunsaturated fatty acid (PUFA) as serum lipids levels reduction and HDL-cholesterol increasing [13], Gamma-linolenic acid (GLA) as rheumatoid arthritis [14], eczema [15], diabetes, multiple trauma, and premenstrual syndrome [16].

Phycobilliproteins are water soluble and highly fluorescent proteins, very stable at physiological $\mathrm{pH}$ [17]. Phycobilliproteins are gaining importance as natural colorants over synthetic colour, as they are nontoxic and non-carcinogenic [18]. Among the phycobiliproteins derived from $S$. platensis, the most abundant is phycocyanin (PC), a brilliant blue colour pigment have greater importance because of its various biological and pharmacological properties e.g. antioxidant [19], antiviral [20], anti-cancer [21], neuro-protective [22], hepatoprotective [23], antitumor [24], radical scavenging [25], radioprotection [26] and anti-inflammatory properties [27]. Carotenoids are structurally diverse lipid soluble pigment have many different biological functions, such as specific coloration, photoprotection, light harvesting and also serve as precursors for many hormones therefore an important medicinal and biotechnological class of natural pigments [28].

In addition, phycobiliproteins are widely used in immunological assays, due to high fluorescence, good storage stability at temperatures between $4-10^{\circ} \mathrm{C}$, high molar absorbance coefficient, high photostability, isoelectric point (IP) close to 4.65 , making them easily linkable to antibodies without changing its spectral properties [29].

Environmental stresses affect growth and biopigment accumulation of microalgae, including nutrients availability, high $\mathrm{pH}$, light, salinity and temperature [30]. The culture conditions can influence the growth phases of Spirulina platensis, causing changes in its composition and proportion of phycobiliproteins [31]. Studies indicated that the quantities of phenolic compound increased by altering the culture conditions and enhance the antioxidant potential of $S$. platensis biomass exploit as a nutritional supplement [32].

Salt stress inhibits plant growth and productivity which are often associated with the decreased photosynthesis [33]. A number of studies have been performed to study the effect of salt stress. Ionic stress due to $0.5 \mathrm{M} \mathrm{NaCl}$ inactivated photosynthetic machinery in Synechococcus $\mathrm{sp}$ [34]. Biswal et al. [35] have revealed that salt stress $(0.5 \mathrm{M} \mathrm{NaCl})$ caused inhibition in photosynthetic electron transport in Brassica junica. The decrease in PS II activity in Chlamidomaonas reinhardtii has been found to be associated with state 2 transitions [36]. In Triticum aestivum light enhanced the inhibitory effect of salt stress on PS II efficiency [37].

The $\mathrm{pH}$ plays important role in the metabolic activities of microalgae. It strongly affects biomass production, chemicals dissociation and cell physiology. Therefore, the effect of different $\mathrm{pH}$ levels on the growth of microalgae was continuously evaluated under different environmental condition $[38,39]$.

The purpose of the present work was to assess the influence of stress conditions including $\mathrm{pH}$, salinity and carbon content on the biomass and biopigment accumulation in S. platensis to optimize the best culture condition for improvement of Phycocyanin (PC), Allophycocyanin (APC), Phycoerythrin (PE), Chlorophyll-a (Chl-a) and Carotenoids (Cart).

\section{Materials and Methods}

\section{Microorganism and culture condition}

The experimental organism S. platensis was isolated from Jal Mahal, Jaipur, Rajasthan (India) and cultivated in Zarrouk's medium

*Corresponding author: Nakuleshwar Dut Jasuja , Assistant Professor, School of Sciences, Suresh Gyan Vihar University, Jagatpura, Jaipur-302025, Rajasthan, India, Tel: +91-9414658277; E-mail: nakuljasuja@gmail.com

Received April 07, 2014; Accepted April 25, 2014; Published April 30, 2014

Citation: Sharma G, Kumar M, Ali MI, Jasuja ND (2014) Effect of Carbon Content, Salinity and $\mathrm{pH}$ on Spirulina platensis for Phycocyanin, Allophycocyanin and Phycoerythrin Accumulation. J Microb Biochem Technol 6: 202-206. doi:10.4172/1948-5948.1000144

Copyright: (c) 2014 Sharma G, et al. This is an open-access article distributed under the terms of the Creative Commons Attribution License, which permits unrestricted use, distribution, and reproduction in any medium, provided the original author and source are credited 
Citation: Sharma G, Kumar M, Ali MI, Jasuja ND (2014) Effect of Carbon Content, Salinity and pH on Spirulina platensis for Phycocyanin, Allophycocyanin and Phycoerythrin Accumulation. J Microb Biochem Technol 6: 202-206. doi:10.4172/1948-5948.1000144

[40]. Experiments to evaluate the effect of different stress conditions were carried out in departmental laboratory. Conical flasks of $100 \mathrm{ml}$ capacity were prepared containing $50 \mathrm{ml}$ S. platensis culture with initial optical density 0.1 for all treatment groups. The cultures placed at west facing window receiving natural day light at temperature $30 \pm 2^{\circ} \mathrm{C}$ and shaken gently thrice a day to avoid clumping and enhance the growth.

\section{Experimental design}

For this study Zarrouk's medium modified with carbon source content, salinity level and $\mathrm{pH}$. All treatment groups are summarized in Table 1.

\section{Analytical methods}

Observations were carried out weekly over a period of 30 days after initial readings. Culture growth was determined by optical density at $670 \mathrm{~nm}$ by using Systronics UV/ VIS spectrophotometer. The effect of these treatments on growth analyzed biochemically for their biopigments by using standard methods suggested by Parson and Strickland [41] for chlorophyll, Bennet and Bogorad [42] for phycobiliproteins, Jenson [43] for carotenoids content of the cultures was measured quantitatively.

\section{Growth measurements}

Measurement of optical density (O.D.) is particularly suitable for determination of growth of $S$. platensis. The basic advantage of turbidity technique in growth rate measurements is the possibility of taking repeated readings on increase in turbidity of the same batch of the suspension of cells.

\section{Chlorophyll estimation}

$5 \mathrm{ml}$ of homogenized cyanobacterial suspension was taken and subjected to centrifugation for 10 minute at $4000 \mathrm{rpm}$. The chlorophyll-a (Chl-a) was extracted from pellet by using $5 \mathrm{ml} 90 \%$ acetone. Place the tube in dark for 24 hour. After extraction period centrifuge the sample for $15 \mathrm{~min}$ at $5000 \mathrm{rpm}$ and collect the supernatant. Read the absorbance at $630 \mathrm{~nm}$ (A630), $645 \mathrm{~nm}$ (A645), and $665 \mathrm{~nm}$ (A665) against 90\% acetone as blank by using Systronics UV/ VIS spectrophotometer and the concentration of Chl-a was calculated using the formula:

\section{$\mathrm{C}=11.6$ A665-1.31 A645-0.14 A630}

The concentration of Chl-a in a given volume of culture can be determined by formula:

$$
\text { Chl-a }((\mathrm{mg} / \mathrm{l}))=\frac{C \times V e}{V c}
$$

\begin{tabular}{|l|l|}
\hline Group & Treatment \\
\hline G1. & Standard $\left(\mathrm{NaHCO}_{3}-18.0 \mathrm{~g} / \mathrm{l}, 0.017 \mathrm{M}\right.$ salinity, $\left.\mathrm{pH} 9\right)$ \\
\hline G2. & $-100 \%$ Carbon deficiency $\left(\mathrm{NaHCO}_{3}-0.0 \mathrm{~g} / \mathrm{l}\right)$ \\
\hline G3. & $-75 \%$ Carbon deficiency $\left(\mathrm{NaHCO}_{3}-4.5 \mathrm{~g} / \mathrm{l}\right)$ \\
\hline G4. & $-50 \%$ Carbon deficiency $\left(\mathrm{NaHCO}_{3}-9.0 \mathrm{~g} / \mathrm{l}\right)$ \\
\hline G5. & $0.2 \mathrm{M}$ Salinity \\
\hline G6. & 0.4 M Salinity \\
\hline G7. & 0.6 M Salinity \\
\hline G8. & 0.8 M Salinity \\
\hline G9. & pH 6 \\
\hline G10. & pH 7 \\
\hline G11. & pH 10 \\
\hline G12. & pH 11 \\
\hline
\end{tabular}

Three replicate were made for each treatment group.

Table 1: Experiments to evaluate the effect of different stress conditions.
$\mathrm{C}=$ Value obtained from above equation
$\mathrm{Ve}=$ Volume of extract $(\mathrm{ml})$
$\mathrm{Vc}=$ Volume of culture (litres)

\section{Phycobiliproteins estimation}

$5 \mathrm{ml}$ of cyanobacterial cell suspension was taken and centrifuged to obtain the pellet for 10 minute at $4000 \mathrm{rpm}$. Wash the pellet with distilled water and Phycobiliproteins were extracted completely from pellet with $5 \mathrm{ml}$ of phosphate buffer $(0.05 \mathrm{M}, \mathrm{pH}$ 6.7) by three times repeated freezing and thawing. Centrifuged the sample for $15 \mathrm{~min}$ at $10,000 \mathrm{rpm}$ and collect the supernatant. The absorbance was read at $562 \mathrm{~nm}$ (A562), $615 \mathrm{~nm}$ (A615), and $652 \mathrm{~nm}$ (A652) against phosphate buffer as blank by using Systronics UV/ VIS spectrophotometer and concentration of phycocyanin (PC), allophycocyanin (APC), and phycoerythrin $(\mathrm{PE})$ were calculated by using the formula:

$$
\begin{aligned}
& \mathrm{PC}=\frac{A 615-0.474(A 652)}{5.34} \\
& \mathrm{APC}=\frac{A 652-0.208(A 615)}{5.09} \\
& \mathrm{PE}=\frac{A 562-2.41(P C)-0.849(A P C)}{9.62}
\end{aligned}
$$

The concentration of phycobiliprotein in a total volume of culture can be determined as follows:

$$
\begin{aligned}
& \text { Phycobiliprotein }(\mathrm{mg} / \mathrm{ml})=\frac{C \times V e}{V c} \\
& \text { C=Value of PC, APC and PE obtained from above equations } \\
& \text { Ve=Volume of extract }(\mathrm{ml}) \\
& V c=\text { Volume of culture }(\mathrm{ml})
\end{aligned}
$$

\section{Carotenoids estimation}

$5 \mathrm{ml}$ of homogenized cyanobacterial suspension was taken and subjected to centrifugation for 10 minute at $4000 \mathrm{rpm}$. Wash the pellet 2-3 times with distilled water to remove traces of adhering salts. Harvested biomass is broken down by the pestle and mortar with 5 $\mathrm{ml}, 90 \%$ acetone and centrifuged the sample at $15 \mathrm{~min}$ at $5000 \mathrm{rpm}$. Collect the supernatant and read the absorbance at $450 \mathrm{~nm}$ (A450) by using Systronics UV/ VIS spectrophotometer. Carotenoids (Cart) concentration calculated by using formula:

$$
\begin{aligned}
& \mathrm{C}=\frac{A 450 \times V \times f \times 10}{2500} \\
& \mathrm{C}=\text { Total amount of Cart }(\mathrm{mg} / \mathrm{ml}) \\
& \mathrm{V}=\text { Volume of extract }(\mathrm{ml}) \\
& \mathrm{f}=\text { Dilution factor }
\end{aligned}
$$

\section{Statistical analysis}

Statistical evaluation of the results was made with SPSS 16.0 (SPSS Inc. Chicago, Illinois, USA). All values were expressed as mean \pm SEM. The differences in the mean of growth and biopigment accumulation of S. platensis were statistically analysed by one-way ANOVA followed by Post hoc Dunnett $t$ test. In view of the exploratory nature of the study, probability values $\mathrm{P} \leq 0.05$ were regarded as statistically significant.

\section{Results and Discussion}

The effect of different stress conditions on the growth of S. plantensis 
Citation: Sharma G, Kumar M, Ali MI, Jasuja ND (2014) Effect of Carbon Content, Salinity and pH on Spirulina platensis for Phycocyanin, Allophycocyanin and Phycoerythrin Accumulation. J Microb Biochem Technol 6: 202-206. doi:10.4172/1948-5948.1000144

expressed in terms of optical density at $670 \mathrm{~nm}$. Growth and biopigment analysis were evaluated weekly during 30 days of cultivation. Post hoc tests included to determine the statistical significance between all groups. It was observed that the biomass of S. platensis was inhibited by all abiotic factors such as $\mathrm{pH}$, salinity, carbon deficiency applied.

Among all the condition tested, G-2 (-100\% carbon deficiency) had shown very significant higher content of chlorophyll-a (Chl-a) i.e. 10.58 \pm 0.40 followed by G-10 (pH 7) i.e. $9.05 \pm 0.33,8.80 \pm 0.63$ in G-5 (0.2 $\mathrm{M}$ salinity) as compared to standard $(8.13 \pm 1.26)$, whereas minimum Chl-a content observed in G-12 (pH 11) i.e. $3.68 \pm 0.20$ (Figure 1,2a-

\section{Growth}

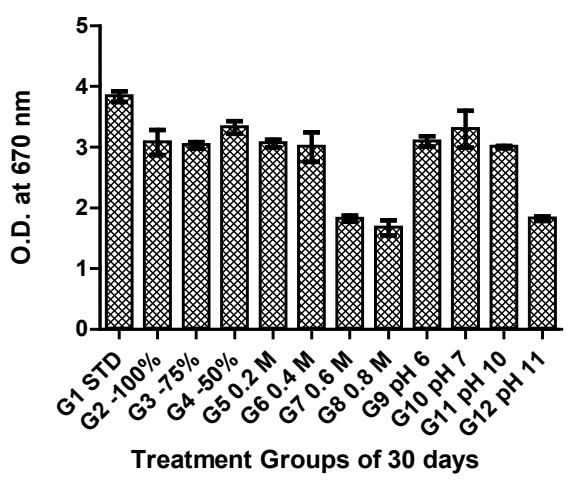

Carotenoid

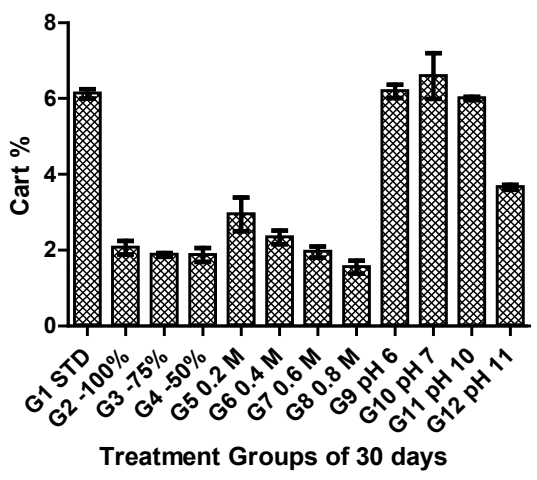

Allophycocyanin

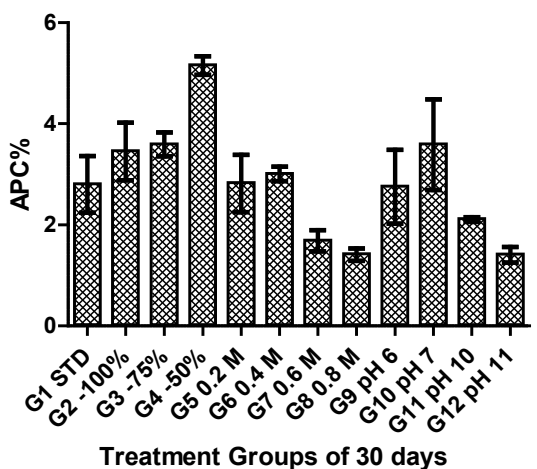

2c). The decreased content of Chl-a mainly due to decreasing the free carbon dioxide concentration in the medium at high $\mathrm{pH}(>10)$ because in this $\mathrm{pH}$ the carbonate form is predominant and the bicarbonate form is the one utilized by $S$. platensis [44].

Carotenoids was found to be higher content in G-10 (pH 7) i.e. 6.59 \pm 0.60 followed by G-9 (pH 6) i.e. $6.19 \pm 0.17$ as compared to standard (6.12 \pm 0.12$)$. G-8 ( $0.8 \mathrm{M}$ salinity) had shown minimum content of carotenoids i.e. $1.55 \pm 0.16$ (Figures 1,2a-2c).

The study revealed that after 30 days of experimental groups

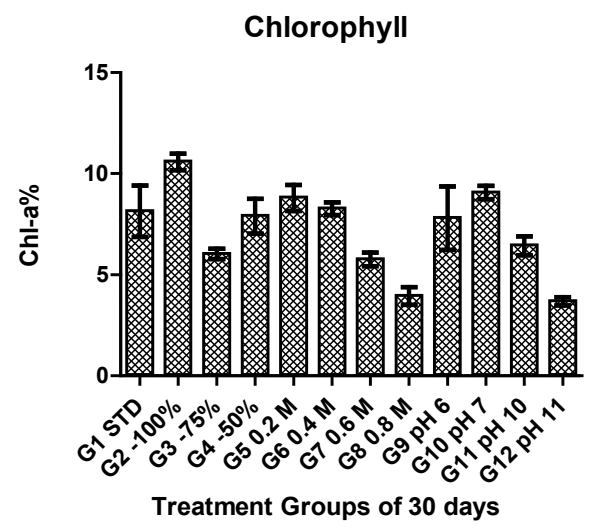

Phycocyanin

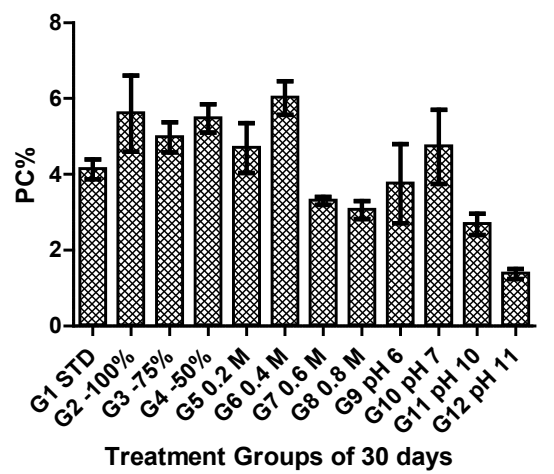

Phycoerythrin

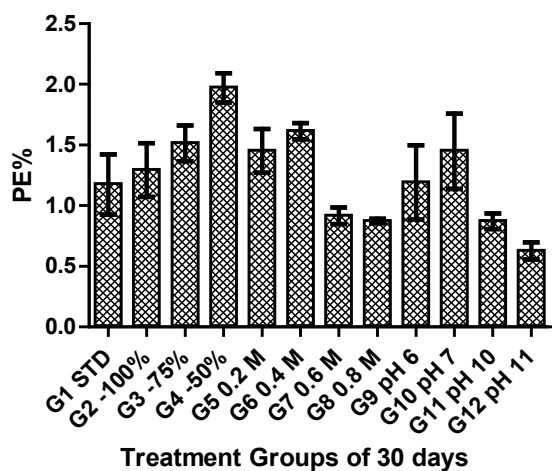

Figure 1: Effect of Carbon content (G2 to G4), Salinity (G5 to G8) and pH (G9 to 12) on Growth, Chlophyll-a, Carotenoids, Phycocyanin, Allophycocyanin and Phycoerythrin content of $S$. platensis. Value are means $\pm S E M(n=3)$. 

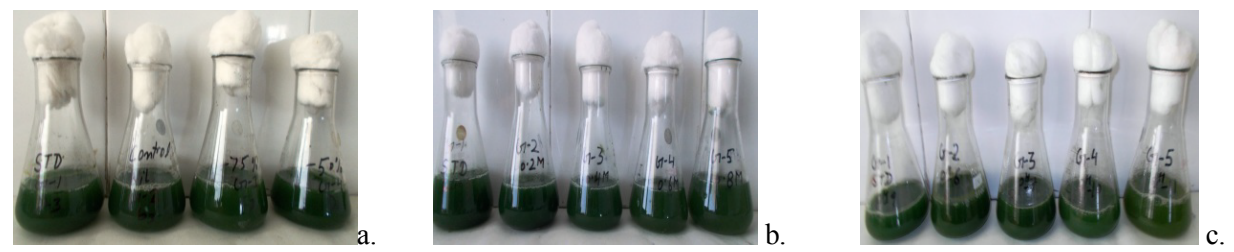

Figure 2: Effect of Carbon content (a), Salinity (b) and pH (c) on Growth, Chlophyll-a, Carotenoids, Phycocyanin, Allophycocyanin and Phycoerythrin content of S. platensis.

had shown significant difference in content of phycocyanin (PC) as compared to standard. G-6 ( $0.4 \mathrm{M}$ salinity) had shown very significant higher content of phycocyanin i.e. $6.01 \pm 0.44$ followed by G-2 $(-100 \%$ carbon deficiency) i.e. $3.60 \pm 1.00,4.72 \pm 0.97$ in $\mathrm{G}-10(\mathrm{pH}$ 7) as compared to standard $\mathrm{G}-1(\mathrm{pH} 9)$ i.e. $4.13 \pm 0.26$. The minimum amount of $\mathrm{PC}$ was found in G-12 (pH 11) i.e. $1.37 \pm 0.13$ as compared to standard (Figure 1,2a-2c).

The G-4 (-50\% carbon deficiency) had shown very significant higher amount of allophycocyanin (APC) i.e. $5.15 \pm 0.18$ followed by G-10 ( $\mathrm{pH}$ 7) i.e. $3.58 \pm 0.89,3.00 \pm 0.14$ in G-6 ( $0.4 \mathrm{M}$ salinity) as compared to standard (2.79 \pm 0.56$)$. G-12 (pH 11) had shown minimum content of APC i.e. $1.40 \pm 0.15$ (Figures 1,2a-2c).

The value of phycoerythrin (PE) found to be significant higher amount in G-4 (-50\% carbon deficiency) i.e. $1.97 \pm 0.12$ followed by G-6 (0.4 salinity) i.e. $1.61 \pm 0.06,1.44 \pm 0.30$ in $\mathrm{G}-10$ (pH 7) as compared to standard. The lowest content of PE was found in G-12 (pH 11) i.e. 0.62 \pm 0.07 as compared to standard (1.71 \pm 0.24$)$ (Figures $1,2 \mathrm{a}-2 \mathrm{c}$ ).

Environmental stress is the factor which affects mass cultivation of S. plantensis due oxidative damage at the cellular level. Oxidative stress is caused by an imbalance between the production of active oxygen and the ability to detoxify the peroxides and free radicals [45]. When different pathways are uncoupled, high energy electrons are transferred to molecular oxygen to form ROS [46]. Disturbances in this normal redox state can cause highly toxic effects through the production of reactive oxygen species (ROS) that damage all components of the cell including proteins, lipids and DNA. To overcome the challenges of oxidative damage $S$. plantensis developed enzymatic antioxidants and non-enzymatic antioxidants [47].

It was observed that an increase of $\mathrm{NaCl}$ concentration caused reduction of growth and total inhibition of chlorophyll-a (Chl-a) biosynthesis of $S$. platensis. This is due to an energy level decline caused by pumping out the entering sodium ions [48]. The increase in the salt concentration caused significant inhibition of electron transport chain and photosystem (PS-II) catalysed electron transport due to damage of reaction centre of PS-II and alterations in water oxidation complex [28].

$\mathrm{pH}$ is one of the environmental factors which affect the physiological growth, metabolic activities and biomass production of $S$. platensis. The results demonstrate that $S$. platensis can adapt to variable $\mathrm{pH}$ conditions as suggested earlier [38,39].

The obtained results showed that any changes in Carbon content led to a significant effect on growth and phycobiliproteins accumulation since photorespiration which protects the photosynthetic membrane against light induced damage at times when carbon assimilation is limited [45]. Photosynthetic rate of S. platensis was higher in the medium containing higher $\mathrm{HCO}^{3-}$. The rate of $\mathrm{CO}_{2}$ fixation in cyanobacteria depends upon the accumulation of inorganic carbon sources [49].

Poza-Carrion et al. [50] revealed that increasing $\mathrm{pH}$ (7-9) significantly increased the phycobiliproteins content in Nostoc sp. Abd El-Baky [51] reported that increasing in salinity levels in nutrient medium led to significant increase in phycocyanin and other soluble proteins content in Spirulina maxima.

\section{Conclusion}

In this paper we have demonstrated that stress conditions influence the production of biomass, phycobiliproteins, chlorophyll-a, carotenoids content of $S$. platensis. The phycobiliproteins contents of S. platensis were increased at $0.4 \mathrm{M} \mathrm{NaCl}$ as well as $\mathrm{pH}$ 7. This can be used in large scale production of phycobiliproteins, which can solve the problem of availability of protein sources in a number of commercial applications.

\section{Acknowledgements}

Authors are thankful to Board of Management \& Academic Council, governed by Honourable Chancellor Mr. Sunil Sharma and Chief Mentor Dr. Sudhanshu for providing cooperation and facility throughout the research work.

\section{References}

1. Dillon JC, Phuc AP, Dubacq JP (1995) Nutritional value of the alga Spirulina World Rev Nutr Diet 77: 32-46.

2. Khan Z, Bhadouria P, Bisen PS (2005) Nutritional and therapeutic potential of Spirulina. Curr Pharm Biotechnol 6: 373-379.

3. Beeker W (2003) Microalgae in human and animal In Richmond A (ed) Handbook of microalgae culture, biotechnology and applied phycology. Blackwell, Oxford, pp.312-352.

4. Vaishampayan A, Sinha RP, Hader DP, Dey T, Gupta AK, et al. (2001) Cyanobacterial biofertilizers in rice agriculture. Bot Rev 67: 453-516.

5. Eriksen NT (2008) Production of phycocyanin--a pigment with applications in biology, biotechnology, foods and medicine. Appl Microbiol Biotechnol 80: 1-14

6. Schwartz J, Shklar G, Reid S, Trickler D (1988) Prevention of experimental oral cancer by extracts of Spirulina-Dunaliella algae. Nutr Cancer 11: 127-134.

7. Hirahashi T, Matsumoto M, Hazeki K, Saeki Y, Ui M, et al. (2002) Activation of the human innate immune system by Spirulina: augmentation of interferon production and NK cytotoxicity by oral administration of hot water extract of Spirulina platensis. Int Immunopharmacol 2: 423-434.

8. Kumar V, Singh A, Bhatnagar AK, Srivastava JN (2013) Methyl Cis-6Octadecenoate, A New Antimicrobial Compound From Spirulina platensis. Asian J Biochem and Pharm Res 2: 6-12.

9. Prakash S, Sasikala SL, Aldous V, Huxley J (2010) Isolation and identification of MDR-Mycobacterium tuberculosis and screening of partially characterized antimycobacterial compounds from chosen marine micro algae. Asian Pac J Trop Med 3: 655-661.

10. Ghosh P, Adhikari U, Ghosal PK, Pujol CA, Carlucci MJ, et al. (2004) In vitro anti-herpetic activity of sulfated polysaccharide fractions from Caulerpa racemosa. Phytochemistry 65: 3151-3157. 
Citation: Sharma G, Kumar M, Ali MI, Jasuja ND (2014) Effect of Carbon Content, Salinity and pH on Spirulina platensis for Phycocyanin Allophycocyanin and Phycoerythrin Accumulation. J Microb Biochem Technol 6: 202-206. doi:10.4172/1948-5948.1000144

11. Piñero Estrada JE, Bermejo Bescós P, Villar del Fresno AM (2001) Antioxidant activity of different fractions of Spirulina platensis protean extract. Farmaco 56 : 497-500

12. Rastogi RP, Sinha RP (2009) Biotechnological and industrial significance of cyanobacterial secondary metabolites. Biotechnol Adv 27: 521-539.

13. Colla LM, Muccillo-Baisch AL, Costa JAV (2008) Spirulina platensis Effects on the Levels of Total Cholesterol, HDL and Triacylglycerols in Rabbits Fed with a Hypercholesterolemic Diet. Braz Arch Biol Technol 51(2): 405-411.

14. Zurier RB, Rossetti RG, Jacobson EW, DeMarco DM, Liu NY, et al. (1996) gamma-Linolenic acid treatment of rheumatoid arthritis. A randomized, placebo-controlled trial. Arthritis Rheum 39: 1808-1817.

15. Worm M, Henz BM (2000) Novel unconventional therapeutic approaches to atopic eczema. Dermatology 201: 191-195.

16. Bugnariu S (1996) Beneficial effect of gamma-linolenic acid-enriched diet therapeutic properties of Oenothera biennis oil (evening primrose oil). Farmacia 44: 3-4.

17. Glazer AN (1999) Chemicals from Microalgae. Z Cohen (Ed.), Taylor and Francis, Philadelphia pp. 263

18. Chaneva G, Furnadzhieva S, Minkova K, Lukavsky J (2007) Effect of light and temperature on the cyanobacterium Arthronema africanum- a prospective phycobiliprotein-producing strain. J Appl Phycol 19: 537-544.

19. Miranda MS, Cintra RG, Barros SB, Mancini Filho J (1998) Antioxidant activity of the microalga Spirulina maxima. Braz J Med Biol Res 31: 1075-1079.

20. Ayehunie S, Belay A, Baba TW, Ruprecht RM (1998) Inhibition of HIV-1 replication by an aqueous extract of Spirulina platensis (Arthrospira platensis). J Acquir Immune Defic Syndr Hum Retrovirol 18: 7-12.

21. Liu Y, Xu L, Cheng N, Lin L, Zhang C (2000) Inhibitory effects of phycocyanin from Spirulina platensis on the growth of human leukemia K562 cells. J Appl Phycol 52: 125-130.

22. Romay Ch, González R, Ledón N, Remirez D, Rimbau V (2003) C-phycocyanin a biliprotein with antioxidant, anti-inflammatory and neuroprotective effects. Curr Protein Pept Sci 4: 207-216.

23. Osman MAH, Sheekh MM (2012) Hepatoprotective effect induced by $\mathrm{NaCl}$ stressed Spirulina platensis: Histopathological, biochemical and histochemical studies. World Applied Science Journal 18: 1370-1380.

24. Li B, Zhang X, Gao M, Chu X (2005) Effects of CD59 on antitumoral activities of phycocyanin from Spirulina platensis. Biomed Pharmacother 59: 551-560.

25. Bhat VB, Madyastha KM (2000) C-phycocyanin: a potent peroxyl radical scavenger in vivo and in vitro. Biochem Biophys Res Commun 275: 20-25.

26. Ivanova KG, Stankova KG, Nikolov VN, Georgieva RT, Minkova KM, et al. (2010) The biliprotein C-phycocyanin modulates the early radiation response: a pilot study. Mutat Res 695: 40-45

27. Romay C, Ledón N, González R (1999) Phycocyanin extract reduces leukotriene B4 levels in arachidonic acid-induced mouse-ear inflammation test. J Pharm Pharmacol 51: 641-642.

28. Pulz O, Gross W (2004) Valuable products from biotechnology of microalgae. Appl Microbiol Biotechnol 65: 635-648

29. Prozyme (2009) C-Phycocyanin (Specifications). Products. [homepage on the Internet]. USA.

30. Pandey JP, Tiwari A, Singh S, Tiwari D (2011) Potential of different light intensities on the productivity of Spirulina maxima. J of Algal Biomass Utilization 2: 9-14.

31. Simeunovic J, Beslin K, Svireev Z, Kovac D, Babic O (2013) Impact of nitrogen and drought on phycobiliprotein content in terrestrial strains. J of Appl Phycol 25: 597-607.

32. Colla LM, Furlong EB, Costa JAV (2007) Antioxidant Properties of Spirulina (Arthospira) platensis Cultivated Under Different Temperatures and Nitrogen Regimes. Braz Arch Biol Technol 50: 161-167.

33. Sreevani $P$, Bhanumathi G, Mohammad SA, Murthy SDS (2011) Effect of high salt stress on photosynthetic electron transport activities in the cyanobacterium, Spirulina platensis. The Bioscan 6(2): 311-313.

34. Allakhverdiev SI, Sakamoto A, Nishiyama Y, Inaba M, Murata N (2000) Ionic and osmotic effects of $\mathrm{NaCl}$-induced inactivation of photosystems I and II in Synechococcus sp. Plant Physiol 123: 1047-1056.

35. Biswal AK, Dilnawaz F, Ramaswamy NK, David KA, Misra AN (2002) Thermoluminescence characteristics of sodium chloride salt-stressed Indian mustard seedlings. Luminescence 17: 135-140.

36. Endo T, Schreiber U, Asada K (1995) Suppression of quantum yield of photosystem II by hyperosmotic stress in Chlamydomonas reinhardtii. Plant Cell Physiol 36: 1253-1258.

37. Mishra SK, Subrahmanyam D, Singhal GS (1991) Interrelationship between salt and light stress on the primary processes of photosynthesis. J Plant Physiol 138: 92-96.

38. Ogbonda KH, Aminigo RE, Abu GO (2007) Influence of temperature and pH on biomass production and protein biosynthesis in a putative Spirulina $\mathrm{sp}$. Bioresour Technol 98: 2207-2211.

39. Celekli A, Yavuzatmaca M, Bozkurt H (2009) Modeling of biomass production by Spirulinaplatensis as function of phosphate concentrations and $\mathrm{pH}$ regimes. Bioresour Technol 100: 3625-3629.

40. Zarrouk C (1966) Contribution a l'etude d'une cyanophycee. Influence de divers facteurs physiques et chimiques sur la croissance et photosynthese de Spirulina maxima (Setch et Gardner) Geitler. PhD Thesis. University of Paris, Paris, France, pp. 4-5.

41. Parson TR, Strickland JDH (1965) Particulate organic matter III. I. pigment analysis III, I.I. Determination of Phytoplankton pigments. J Fish Res Bd Canada 18: 117-127.

42. Bennett A, Bogorad L (1971) Properties of subunits and aggregates of bluegreen algal biliproteins. Biochemistry 10: 3625-3634.

43. Jensen A (1978) Chlorophylls and carotenoids. In: Hellebust JA, Craigie JS (eds) Handbook of phycological methods, physiological and biochemical methods. Cambridge University Press, Cambridge, pp. 59-70.

44. Vonshak A, Kancharaksa N, Bunnag B, Tanticharoen M (1996) Role of light and photosynthesis on the acclimation process of the cyanobacteria Spirulina platensis to salinity stress. J Appl Phycol 8:119-124.

45. Poonia S, Priya K (2013) Environmental stress: response, mechanism and its regulation in cyanobacterium spirulina. Int J Bioassays 2: 1000-1010.

46. Nobuhiro S, Mittler $R$ (2006) Reactive oxygen species and temperature stresses: A delicate balance between signaling and destruction, Physiologia Plantarum 126: 45-51.

47. Cameron JC, Pakrasi HB (2010) Essential role of glutathione in acclimation to environmental and redox perturbations in the cyanobacterium Synechocystis sp. PCC 6803. Plant Physiol 154: 1672-1685.

48. Ayachi S, El Abed A, Dhifi W, Marzouk B (2007) Chlorophylls, proteins and fatty acids amounts of arthrospira platensis growing under saline conditions. Pak Biol Sci 10: 2286-2291.

49. Chauhan S, Kaithwas V, Kachouli R, Bhargava S (2013) Productivity of the cyanobacterium Spirulina platensis in culture using high bicarbonate and different nitrogen sources. American J Plant Physiol 8: 17-31.

50. Poza-Carrion C, Fernadez-Valiente E, Fernadez- Pinas F, Leganes F (2001) Acclimation of photosynthetic pigments and photosynthesis of the cyanobacterium Nostoc sp. Strain UAM 206 to combined fluctuations of irradiance, $\mathrm{pH}$ and inorganic carbon availability. Plant Physiol 158: 1455-1461.

51. Abd El-Baky HH (2003) Over production of phycocyanin pigment in blue green alga Spirulina sp. and its inhibitory effect on growth of Ehrlich ascites carcinoma cells. Med Sci 3: 314-24. 